\title{
Development of a Small Downdraft Biomass Gasifier for Developing Countries
}

\author{
M. A. Chawdhury ${ }^{\mathrm{a}^{*}}$, and K. Mahkamov \\ anformation Management Division, Power Grid Company of Bangladesh Ltd., Dhaka-1212, \\ Bangladesh \\ ${ }^{\mathrm{b}}$ School of Engineering and Computing Sciences, Durham University, South Road, Durham DH1 \\ 3LE, UK
}

Received 25 July 2010, accepted in final revised form 29 November 2010

\begin{abstract}
Biomass gasification has been receiving increasing attention as a potential renewable energy source for the last few decades. This attempt involved designing, developing and testing a small downdraft biomass gasifier JRB-1 (6-7 kW) at Durham University, UK. The gasifier was built of stainless steel pipes, sheets and other fittings and tested for wood chips and pellets. The composition, moisture content and consumption of biomass feedstock ( $3.1 \mathrm{~kg} / \mathrm{hr}$ for wood chips, $2.9 \mathrm{~kg} / \mathrm{hr}$ for pellets), temperature inside the reaction zone $\left(950-1150{ }^{\circ} \mathrm{C}\right)$, primary air flow rate $\left(0.0015 \mathrm{~m}^{3} / \mathrm{s}\right)$ and exit temperature of the producer gas $\left(180-220^{\circ} \mathrm{C}\right)$ was measured. The main constituents of syngas included nitrogen (50-56\%), carbon monoxide (19-22\%), hydrogen (12-19\%), carbon dioxide (10-12\%) and a small amount of methane (1-2\%). These results were used in Engineering Equation Solver (EES) software to obtain the lower calorific value of syngas $\left(4424-5007 \mathrm{~kJ} / \mathrm{m}^{3}\right)$ and cold gas efficiency (62.5$69.4 \%$ ) of the gasifier, which were found close to the calculated values. Again the thermal efficiency was calculated as $90.1-92.4 \%$. Being comparatively easy to build, downdraft gasifiers like JRB-1 are likely to be the most appropriate technology for developing countries as a source of decentralized power supply and for development in agricultural sector.
\end{abstract}

Keywords: Biomass gasification; Syngas; Emission; Renewable energy.

(C) 2011 JSR Publications. ISSN: 2070-0237 (Print); 2070-0245 (Online). All rights reserved. doi:10.3329/jsr.v3i1.5613 J. Sci. Res. 3 (1), 51-64 (2011)

\section{Introduction}

One of the greatest achievement of man since the beginning of civilization has been the discovery and control of various forms of energy. Energy is a strategic input necessary for socio-economic development. Worldwide, $80 \%$ of all energy used by human comes from fossil fuels [1]. Such immense exploitation could exhaust theses resources within few decades and imposes a real threat to the environment mainly it would seem through global

\footnotetext{
*Corresponding author: adil99mebuet@yahoo.com.sg
} 
warming. Therefore scientists all over the world are trying to tap the sources of energy that are inexhaustible, cheap, absolutely pollution free and specially suited to deserts and isolated places [1-8].

Biomass is a potential renewable energy source for developing countries. It provides more than $300 \mathrm{GW}$ of energy for domestic cooking [2]. One of the attractive technologies for alternative fuel from biomass is called gasification and the equipment used in the gasification process is commonly referred to as gasifier.

Gasification is a process of converting carbonaceous materials (biomass/coal) through incomplete combustion at temperatures of more than $1000^{\circ} \mathrm{C}$ to combustible gases consisting of carbon monoxide, hydrogen, carbon dioxide and small amounts of methane etc. This gas mixture is commonly known as a 'producer gas' or 'syngas'. The survey carried out in 2003 suggested that at present throughout the world there are 468 gasifiers in operation covered by 163 commercial gasification projects [2]. A few of them are downdraft gasifiers. This downdraft gasifier could be the most promising types of gasifier for its simplicity and suitability for engine applications.

The present work is an attempt intended to design, develop and test a small downdraft biomass gasifier JRB-1 at Durham University. The fuel used is both wood chips and pellets. A simple design is made and its perspective applications are assessed for developing countries. The performances of the gasifier for different fuels are compared are with the simulated outputs of Engineering Equation Solver (EES) software.

\section{Downdraft Gasifier}

\subsection{General features}

A schematic diagram of a downdraft gasifier is shown in Fig. 1. The features of such a gasifier can be stated as follows:

a. Primary gasification air is introduced at or above the oxidation zone and producer gas removed from bottom of the gasifier.

b. Fuel and gas move in the same direction (co-current).

c. On their way down acid and tarry distillation products pass through glowing bed of charcoal and converted to permanent gases.

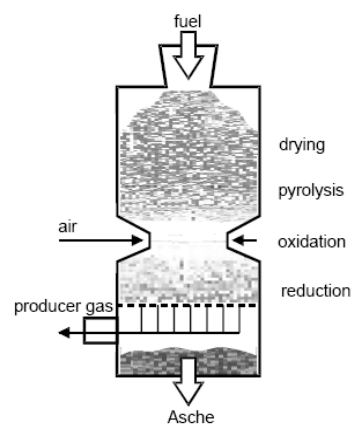

Fig. 1. Schematic diagram of a downdraft gasifier. 
Advantages of such a gasifier are the possibility of producing tar free gas suitable for engine applications, flexible adaptation of gas production to load, less environmental objection, and higher fuel conversion rate.The major drawback is the inability to operate on a number of unprocessed fuels particularly fluffy and low density materials.

\subsection{Processes and reaction chemistry for the downdraft gasifier}

As the feedstock proceeds through the different section of a downdraft gasifier the following physical, chemical and thermal processes may take place simultaneously or sequentially depending on the properties of feedstock and the design of the gasifier.

Drying zone or bunker section: Biomass is introduced into the downdraft gasifier at the top. Due to the heat transfer from the lower part of the gasifier, drying of biomass takes place in the bunker section.

$$
\text { Moist feedstock }+ \text { Heat } \rightarrow \text { Dry feedstock }+\mathrm{H}_{2} \mathrm{O}
$$

The water vapour flows downwards and adds to the vapour formed in the oxidation zone. Part of this reduces to hydrogen and the rest ends up as moisture in the gas.

Pyrolysis zone: At temperatures above $250{ }^{\circ} \mathrm{C}$, pyrolyzing of the biomass feedstock occurs. It is a complicated process. Here large molecules (cellulose, hemi-cellulose and lignin) are broken down into carbon (char) and medium size molecules (volatiles) [4].

$$
\text { Dry feedstock }+ \text { Heat } \rightarrow \text { Char }+ \text { Volatiles }
$$

Oxidation or combustion zone: An oxidation or burning zone is formed in the section where air/oxygen is supplied. These combustion reactions are highly exothermic and cause a rapid temperature increase up to $1100-1500{ }^{\circ} \mathrm{C}$. The reactions are as follows $[5,6]$ :

$$
\begin{array}{ll}
\mathrm{C}+\mathrm{O}_{2}=\mathrm{CO}_{2} & (+393 \mathrm{MJ} / \mathrm{kg} \text { mole }) \\
2 \mathrm{H}_{2}+\mathrm{O}_{2}=2 \mathrm{H}_{2} \mathrm{O} & (+242 \mathrm{MJ} / \mathrm{kg} \text { mole })
\end{array}
$$

Instead of generating heat, another important function of the oxidation zone is to convert and oxidize virtually all condensable products coming from the pyrolysis zone.

Reaction or reduction zone: Here, the sensible heat of the gases and charcoal is converted into the chemical energy of the producer gas. The following reactions take place $[5,6]$ :

$$
\begin{array}{ll}
\mathrm{C}+\mathrm{CO}_{2}=2 \mathrm{CO} & (-164.9 \mathrm{MJ} / \mathrm{kg} \text { mole }) \\
\mathrm{C}+\mathrm{H}_{2} \mathrm{O}=\mathrm{CO}+\mathrm{H}_{2} & (-122.6 \mathrm{MJ} / \mathrm{kg} \text { mole }) \\
\mathrm{CO}+\mathrm{H}_{2} \mathrm{O}=\mathrm{CO}_{2}+\mathrm{H}_{2} \quad(+42.3 \mathrm{MJ} / \mathrm{kg} \text { mole })
\end{array}
$$




$$
\begin{array}{ll}
\mathrm{C}+2 \mathrm{H}_{2}=\mathrm{CH}_{4} & (+75 \mathrm{MJ} / \mathrm{kg} \text { mole }) \\
\mathrm{CO}+3 \mathrm{H}_{2}=\mathrm{CH}_{4}+\mathrm{H}_{2} \mathrm{O} & (-205.9 \mathrm{MJ} / \mathrm{kg} \text { mole })
\end{array}
$$

The mixture of gases produced in this zone is called syngas or producer gas.

\section{Design and Development of the Downdraft Gasifier}

The prime reason behind the attempt to develop JRB-1 downdraft gasifier at Durham University was its capability to produce low tar containing producer gas suitable for engine applications. The first step was to find a feasible design, which could be taken as the basis for the gasifier construction. It was also decided that, at this stage, syngas would be burnt in a simple burner rather than feeding it to an engine. After a few technical considerations, it was decided to develop approximately 6-7 $\mathrm{kW}$ capacity downdraft gasifier based on the 'Fluidyne Gasifier' model with significant modifications.

\subsection{Development of model of the gasifier}

It was decided that the main body of the gasifier would be divided into 3 pieces of pipes for easy fabrication of the internal parts. These three sections would be top cylinder (fuel chamber), middle cylinder (reaction chamber) and bottom cylinder (ash chamber). For reliability, longer life and experimentation, it was planned to build with stainless steel.

Depending on the available materials and the original Fluidyne model, drawings for different parts and the full gasifier were developed with SolidWorks drawing package
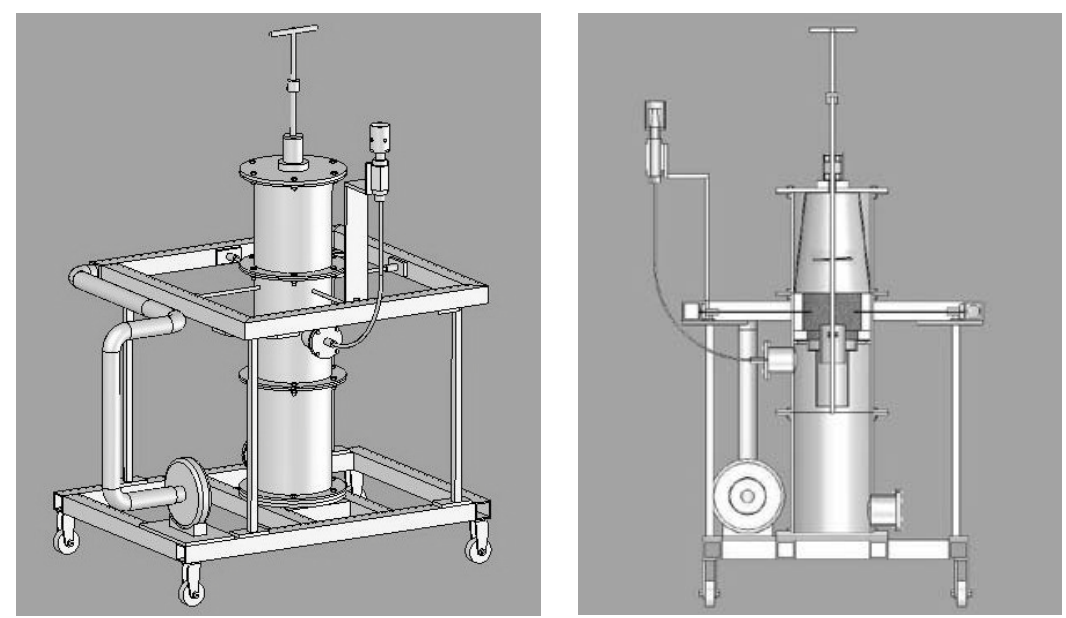

Fig. 2. Schematic and cross-sectional view of JRB-1 gasifier model [SolidWorks model].

After developing SolidWorks model of gasifier, materials were collected for fabrication. This included stainless steel tubes/pipes, sheets, flanges; straight fittings, copper gaskets, steel and braze metals, gate valve and high temperature bearings etc. 
Non-metal items included sealing materials/gaskets, thermal resistant cement (refractory castable $160 \mathrm{LC}$ cement, service temperature $1600{ }^{\circ} \mathrm{C}$ ), insulating tape etc.

The electrical equipment included an air supply fan with duct and control system, thermocouples and gas velocity measuring speed-gun.

\subsection{Manufacture of different parts and assembly}

At the beginning of the construction, all the pipes/tubes and sheet metals were fabricated according to the drawings. The gasifier was sectionalized into various parts described in the following subsections.

\subsubsection{Top part or fuel chamber}

The top cylinder was made of $6.3 \mathrm{~mm}$ thick, $219 \mathrm{~mm}$ outer diameter and $272 \mathrm{~mm}$ length stainless pipe. It contained bunker and pyrolysis zones. Biomass feedstock dried here due to the convective and radiation heat transfer from the lower parts of the gasifier. A conical tube of $2.5 \mathrm{~mm}$ thick stainless steel was placed inside to avoid 'fuel bridging'. The capacity of the fuel chamber was approximately $5 \mathrm{~kg}$ of wood chips/pellets.
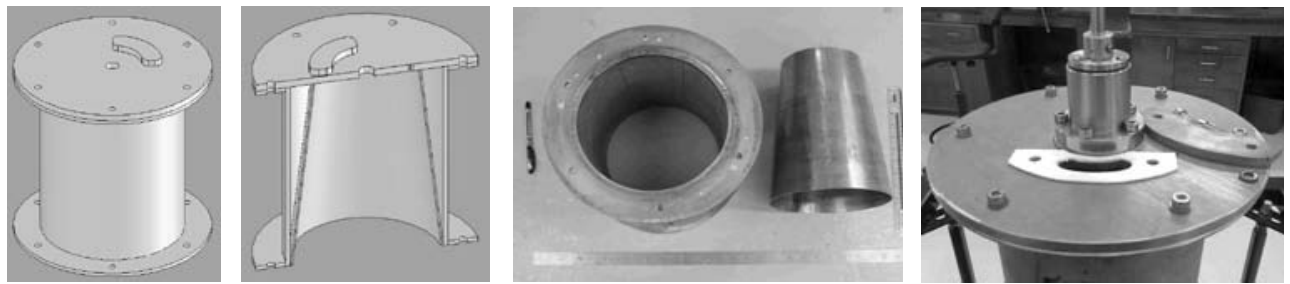

Fig. 3. Schematic, cross sectional and manufactured view of top part.

\subsubsection{Middle part or reaction chamber}

This part is the heart of the gasifier where the syngas is produced. It contains the oxidation zone and the throat section. Fuels flow down by gravity. The middle cylinder was made of $6.3 \mathrm{~mm}$ thick, $219.1 \mathrm{~mm}$ outer diameter and $320 \mathrm{~mm}$ long stainless steel pipe. Inside this chamber there was a slab of thermal resistant concrete to provide insulation around hot zone. There were 4 holes in middle of the slab for the air supply nozzles. Two flanges were mounted at the top and bottom to be attached to other chambers.
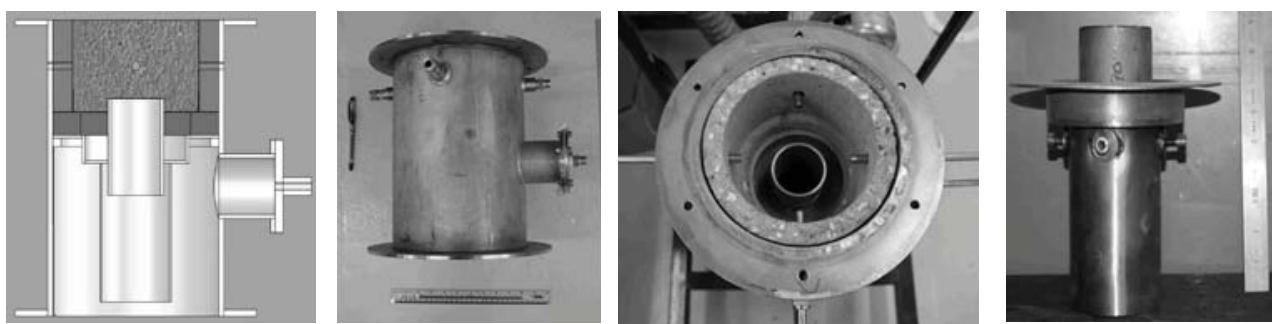

Fig. 4. Cross sectional and manufactured view of middle part and throat section. 
Generally, two methods were applied to obtain an even high temperature distribution. Firstly, reducing the cross sectional area at a certain height ('throat' concept) and spreading the air inlet nozzles over the reduced cross sectional area. The throat section was made of two concentric stainless steel pipes of 70 and $88 \mathrm{~mm}$ diameter with annular plates. The whole assembly seemed like a 'pocket' and gave the facility to change the depth of the throat pipe to modify the distance between the nozzles and the top of the reduction zone in the simplest way. The gas outlet pipe was made of 70mm SS pipe.

\subsubsection{Bottom cylinder or ash chamber}

The lower cylinder contained the ash zone where the ash resulting from the gasification process of the biomass was stored and occasionally removed. The ash from the reaction chamber could fall down freely through the grate. The bottom chamber was made of 219.1 mm diameter and $325 \mathrm{~mm}$ long cylinder.
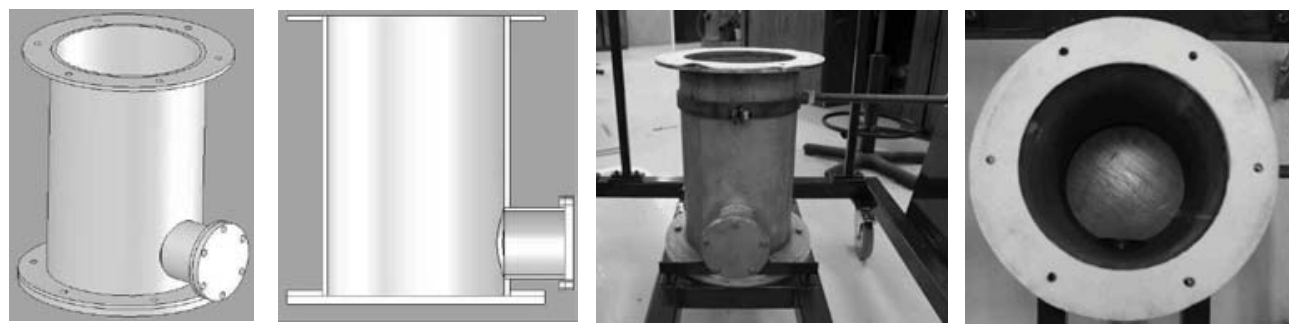

Fig. 5. Schematic, cross sectional and manufactured view of bottom part.

\subsubsection{Stirrer and grate}

Because of the fact that fuels often produce bridges, it is often required to use a stirrer. A moveable grate at the bottom is generally considered necessary. This makes it possible to stir the glowing charcoal bed in the reduction zone and thus helps to prevent blockages which can lead to obstruction of gas flow. In JRB-1 gasifier, stirrer and grate were mounted on a single stainless steel rod (15 mm diameter) inserted from the top of the gasifier. The rod was occasionally rotated with a removable T-shaped handle.
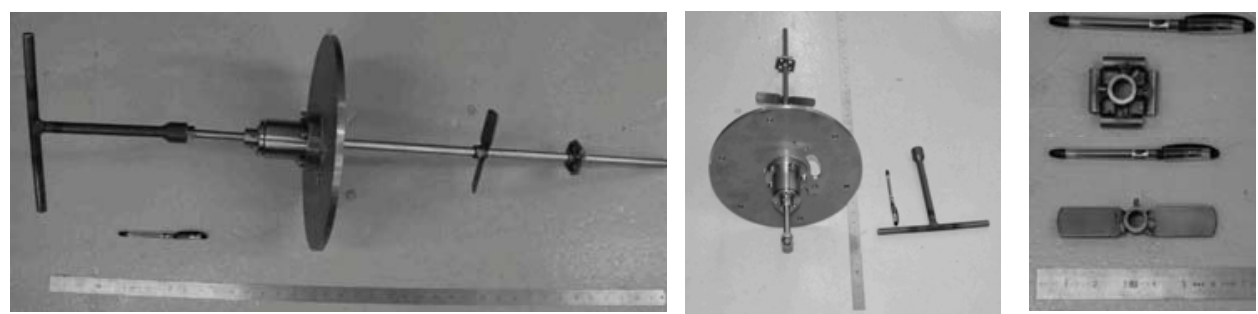

Fig. 6. Stirrer and moveable grate connected with top cover plate. 


\subsubsection{Air supply system}

Primary air in the oxidation zone was supplied by 4 air inlet nozzles $(7 \mathrm{~mm}$ inner diameter) placed in the middle of the reaction chamber. These nozzles were connected to the square shape primary air inlet manifold placed around the middle cylinder. The manifold was constructed from 50x50x4 mm square mild steel pipes. Air was supplied to the manifold from a variable speed SAVT metal case centrifugal fan (Model: SAVT100L, 230V, nominal speed $2550 \mathrm{rpm}$, maximum air volume $0.065 \mathrm{~m}^{3} / \mathrm{s}$ at $40{ }^{0} \mathrm{C}$ ).
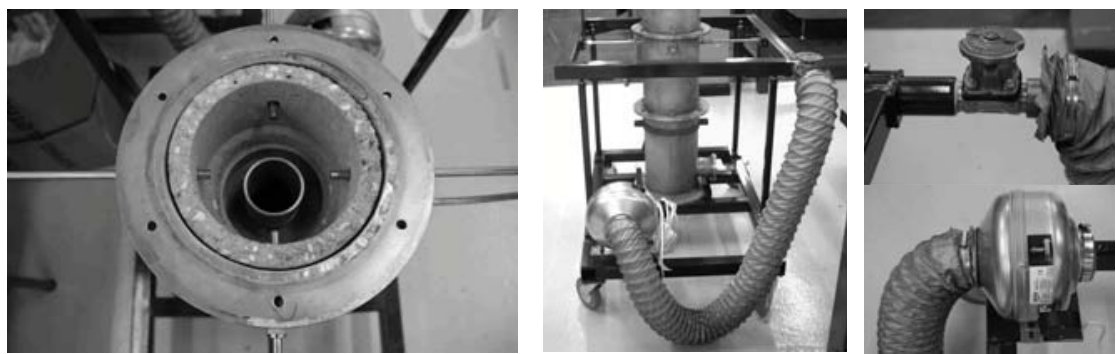

Fig. 7. Air inlet nozzles, air supply system, gate valve and centrifugal fan.

\subsubsection{Other accessories and assembling}

A gradually bending stainless steel gas outlet pipe was connected to a simple burner. For every flange joint, top and bottom cover plates; a high temperature ceramic paper gasket (2 mm) was used. Again insulation material (Webbing tape, TW G3) was placed on the body. Finally, the gasifier was placed on a trolley for easily movement to a suitable place for testing. After assembling the final shape of the JRB-1 gasifier became as follows.
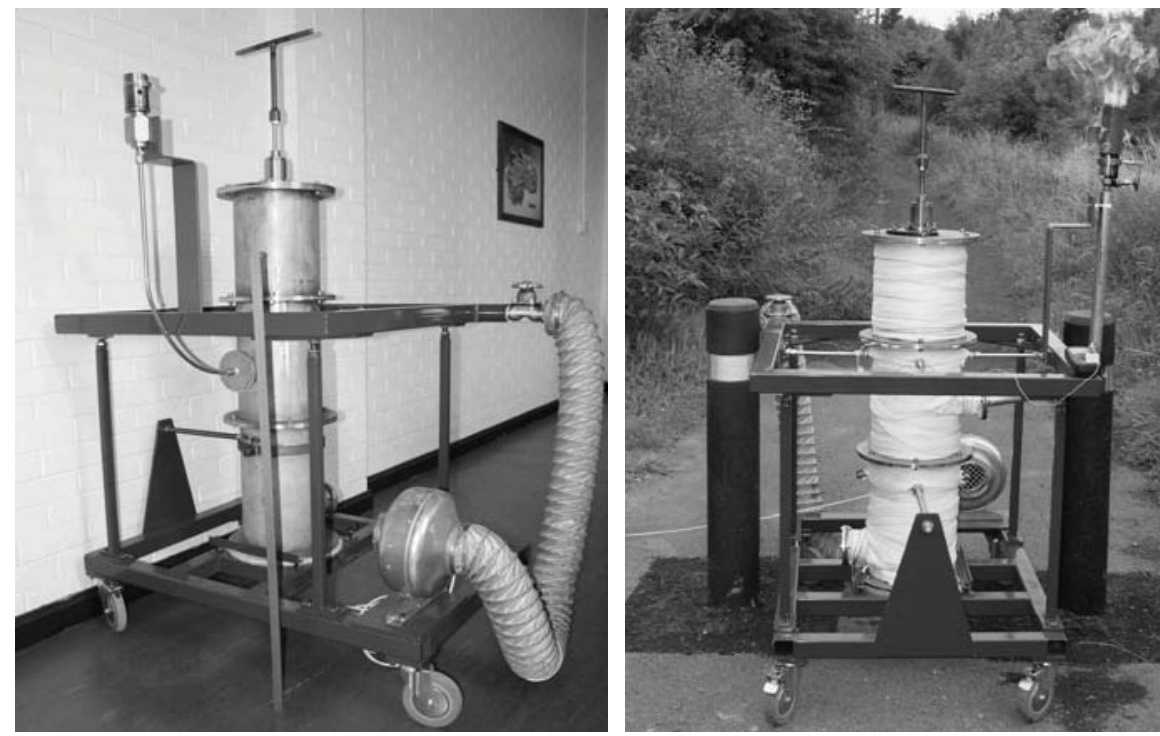

Fig. 8. Final manufactured form and testing of the JRB-1 gasifier. 


\section{Operation and Testing of Gasifier}

\subsection{Operating procedure}

The JRB-1 gasifier was operated and tested in the following steps:

(i) Before starting, all the parts (flange attachments, fittings) of the gasifier were properly tightened and it was placed on open space.

(ii) The electrical fan for primary air supply was kept switched off.

(iii) The top cover of the gasifier was opened.

(iv) A thin layer of charcoal was placed near the throat (pocket area) of the oxidation zone and some of them were wetted with fire lighter (liquid).

(v) The charcoal bed was ignited with a torch and fan was switched on to supply sufficient air/oxygen to initiate the combustion.

(vi) The top cover plate was closed and tightened.

(vii) Then the gasifier was loaded with biomass through fuel feeding hole.

(viii) During the second run, gasifier was loaded first and ignition was initiated through the ash hole. Finally an ignition port was drilled to initiate combustion.

(ix) The primary air supply was full at the starting of gasifier and then maintained around $35 \%$ of the stoichiometric condition to ensure the partial combustion of the biomass with the help of a fan-controller, gate valve and air flow meter.

(x) After 5 minutes, the producer gas in the form of thick white smoke came out through the burner.

(xi) The producer gas was ignited with a firing-torch at the burner.

(xii) A yellowish-red flame was observed and continued to ignite for 91 minutes.

(xiii) To stop the gasifier, first the fan was switched-off then the gate valve in the air supply channel was closed to completely stop the primary air supply.

(xiv) The gasifier was ultimately stopped after closing the air supply and left in an open space until it cooled down and all gases came out (more than 6 hours).

During the testing of the gasifier the following measurements were taken:

(a) Primary air velocity and volumetric flow rate of syngas was measured by a VELOCICALC Air Velocity instrument. The average air velocity of primary air during the experiment was found in between 6.35 and $8.75 \mathrm{~m} / \mathrm{s}$ at the gas outlet pipe of ID16 mm. Therefore, volumetric air flow rate was between 0.00127 and $0.0017 \mathrm{~m}^{3} / \mathrm{s}$. The best result was obtained at $0.0015 \mathrm{~m}^{3} / \mathrm{s}$ of air flow rate.

(b) Average solid biomass fuel consumption was measured using digital weight machine. The biomass feedstock was dried in the BINDER electrical oven.

(c) Temperature in the reaction zone and gas outlet zone were measured with the help of a K-type thermocouple and an Autoranging multimeter. Throughout the 
testing, the temperature of the hot zone was found up to $1160{ }^{\circ} \mathrm{C}$. The temperature of producer gas at the generator exit was $180-230{ }^{\circ} \mathrm{C}$.

\subsection{Safety issues during testing}

Since the gasifier produced syngas contained toxic and flammable carbon monoxide, methane, hydrogen etc., and the temperature in the oxidation zone was more than $1100{ }^{\circ} \mathrm{C}$, a number of safety measures listed below were taken to avoid toxic, fire and explosion hazards.

a. Before starting, every joint and fitting was properly tightened to avoid leakage.

b. Tests were carried out in open space and the combustion products were exhausted to the atmosphere.

c. Biomass feedstocks were handled with hand gloves.

d. Safety glass, rigid sole footwear and hand gloves were used during testing.

e. A standard first aid box and fire extinguishing equipment $\left(\mathrm{CO}_{2} /\right.$ dry powder $)$ were kept ready for emergencies.

f. After testing, the gasifier was cooled down for a 6 hours period and all the gas was ventilated in open air and the ash was disposed of in the waste bin.

\subsection{Fuel tested}

The downdraft biomass gasifier was tested for two types of fuels i.e. wood chips and wood pellets. The fuels were processed before loading into the fuel chamber. Both wood chips and pellet were supplied by BTL Woodshed Limited, Bp Auckland, Durham.
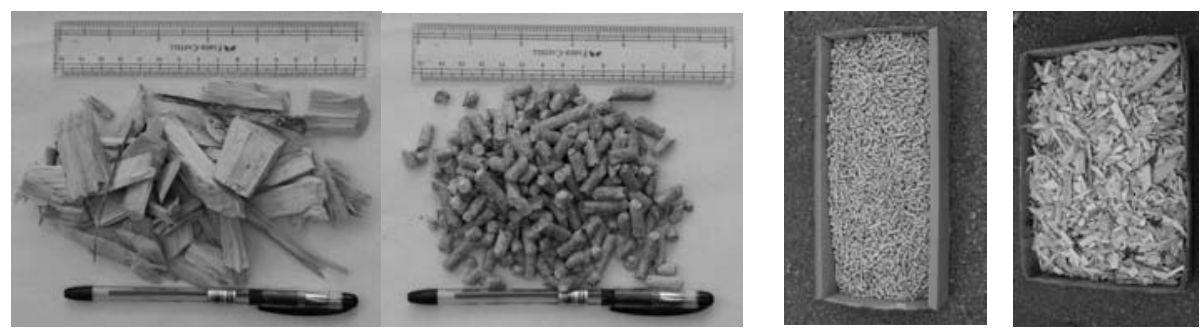

Fig. 9. Wood chips and wood pellets tested in the JRB-1 gasifier.

The average sizes of the woodchips were $30-70 \mathrm{~mm}$ and wood pellets were $15-30 \mathrm{~mm}$. Wood chips/pellets were naturally dried for 2 days and electrical oven dried at $105{ }^{\circ} \mathrm{C}$ for 3-4 hours. Average properties of the fuels (wood chips and wood pellets) used in JRB-1 gasifier were determined through laboratory testing. Results are given in Table 1. 
Table 1. Average properties of the fuel used in the JRB-1 gasifier from laboratory test.

\begin{tabular}{lcc}
\hline \multicolumn{1}{c}{ Properties } & Wood chips & Wood pellets \\
\hline Apparent density $\left(\mathrm{kg} / \mathrm{m}^{3}\right)$ & $280-550$ & $600-700$ \\
\hline Ultimate analysis (dry basis) & & \\
Carbon (weight, \%) & $46-54$ & $41-48$ \\
Hydrogen (weight, \%) & $4-6$ & $6-8$ \\
Oxygen (weight, \%) & $38-43$ & $42-46$ \\
Proximate analysis (wet basis) & & \\
Moisture content (\%) & 7.36 & 8.55 \\
Volatile matter (\%) & $65-75$ & $80-85$ \\
Fixed carbon (\%) & $15-20$ & $6-10$ \\
Ash (\%) & 0.338 & 0.574 \\
\hline
\end{tabular}

\section{Result and Discussion}

The gasifier was first fired on $10^{\text {th }}$ July 2009 using wood chips as fuel. Next few days, it was tested with wood pellets and chips and performance in different conditions was observed. Based on these, few modifications were conducted in design. During the first run, unstable flame and tar came out through the burner. The reasons identified were the low temperature in the oxidation zone, short residence time of the tarry vapours due to high gas velocity in the hot zone and wet wood chips. Therefore the gas outlet pipe was replaced with a larger bore $(\mathrm{OD}=34 \mathrm{~mm})$ steel pipe. Another important modification was made in the burner to reduce gas velocity. Finally the hot parts of the gasifier were insulated with webbing tape (TW G3) to reduce heat loss and an ignition port was made close to the reaction zone. With these modifications it was possible to obtain up to 1160 ${ }^{\circ} \mathrm{C}$ temperature in the hot zone and stable flame was observed for 91 minutes.

\subsection{Biomass fuel consumption}

When the gasifier was run on wood pellets, it consumed around 4400 gm of fuel to give a stable flame for 91 minutes (approximately $2.9 \mathrm{~kg} / \mathrm{hr}$ ). On the other hand, when it was loaded with wood chips, fuel consumption was $3.1 \mathrm{~kg} / \mathrm{hr}$.

\subsection{Producer gas composition}

Using the moisture content of feedstocks, the composition of producer gas and its changes were calculated from wood gas composition graphs [8]. These are given in Tables 2 and 3. 
Table 2. The composition of producer gas (\% of volume) for JRB-1 gasifier.

\begin{tabular}{lllrrrrl}
\hline Fuels & $\begin{array}{l}\text { Moisture } \\
\text { dry (\%) }\end{array}$ & $\mathrm{CO}$ & $\mathrm{H}_{2}$ & $\mathrm{CH}_{4}$ & $\mathrm{CO}_{2}$ & $\mathrm{~N}_{2}$ & $\begin{array}{l}\text { Moisture in gas } \\
(\mathrm{kg} / \mathrm{kg} \text { of wood) }\end{array}$ \\
\hline Wood Chips & 7.36 & $21-22$ & $17-19$ & $1-1.5$ & $10-11$ & $50-55$ & 0.1 \\
Wood Pellets & 8.55 & $19-21$ & $12-19$ & $1-2$ & $11-12$ & $52-56$ & 0.12 \\
\hline
\end{tabular}

Table 3. The change in composition of producer gas (\% of volume) for JRB-1 gasifier.

\begin{tabular}{lccccccc}
\hline Fuels & Temp $\left({ }^{0} \mathrm{C}\right)$ & $\mathrm{CO}$ & $\mathrm{H}_{2}$ & $\mathrm{CH}_{4}$ & $\mathrm{CO}_{2}$ & $\mathrm{~N}_{2}$ & $\begin{array}{c}\text { Moisture } \\
(\mathrm{kg} / \mathrm{kg})\end{array}$ \\
\hline Wood Chips & $180-230$ & 23 & 20 & 1.5 & 11 & 43.7 & 2 \\
Wood Pellets & $220-240$ & 22 & 20.5 & 2 & 11.5 & 44 & 2 \\
\hline
\end{tabular}

\subsection{Cold gas efficiency calculation of JRB-1 gasifier (experimental)}

The relevant formula used for the cold gas efficiency of downdraft gasifier is $[4,6]$ :

$$
\eta_{g}=\frac{H_{g} \times Q_{g}}{H_{s} \times M_{s}} \times 100 \%
$$

If syngas is used for direct burning works, efficiency can be defined as follows $[4,6]$ :

$$
\eta_{t h}=\frac{\left(H_{g} \times Q_{g}\right)+\left(Q_{g} \times \rho_{g} \times C_{p} \times \Delta T\right)}{H_{g} \times M_{g}} \times 100 \%
$$

For JRB-1 gasifier, the parameters in the equations are defined below along with their present experimental values (some parameter-values are taken from other sources $[5,6,8]$ ):

$H_{\mathrm{g}}=$ Lower heating value (LHV) of syngas $=5000 \mathrm{~kJ} / \mathrm{m} 3$ (for wood chips); 4400 $\mathrm{kJ} / \mathrm{m}^{3}$ (for wood pellets) [6],

$Q_{\mathrm{g}}=$ volume flow rate of gas $=0.0015 \mathrm{~m}^{3} / \mathrm{s}$ for both wood chips and pellets,

$H_{\mathrm{s}}=\mathrm{LHV}$ of solid fuel = 13-15000 kJ/kg (wood chips); 4-17000 kJ/kg (pellets) [5],

$M_{\mathrm{s}}=$ solid fuel consumption $=0.000867 \mathrm{~kg} / \mathrm{s}$ (wood chips); $0.000805 \mathrm{~kg} / \mathrm{s}$ (pellets),

$\rho_{\mathrm{g}}=$ density of producer gas, $1.3 \mathrm{~kg} / \mathrm{m}^{3}$ (from gas composition [8]),

$C_{\mathrm{p}}=$ specific heat of the producer gas, $1.45 \mathrm{~kJ} / \mathrm{kg} \mathrm{K}$ (from gas composition [8]),

$\Delta T=$ temperature difference between the gas outlet and fuel inlet, $200{ }^{\circ} \mathrm{C}=473 \mathrm{~K}$.. 
Using the values efficiencies and thermal power were found as follows:

$\eta_{\mathrm{g}}=$ Overall cold gas efficiency $=66.66 \%$ (for wood chips) and $=58.89 \%$ (for wood pellets),

$\eta_{\mathrm{th}}=$ Thermal efficiency of the gasifier $=90.1 \%$ (wood chips), and 92.5\% (for wood pellets),

$P_{\mathrm{g}}=$ Thermal power of the syngas, $Q_{\mathrm{g}} \times H_{\mathrm{g}}=0.0015 \times 4400=6.636 \mathrm{~kW}$ (for pellets), $P_{\mathrm{th}}=$ Thermal power consumption (full load), and $P_{\mathrm{g}} / \eta_{\mathrm{th}}=6.636 / 0.924=7.18 \mathrm{~kW}$.

\subsection{Gasifier performance evaluation using engineering equation solver (EES) software}

The producer gas obtained from the different feedstocks (wood chips and pellets) was analyzed with a special model of Engineering Equation Solver (EES) simulation software particularly suitable for a stationary model of downdraft gasifier. The simulated performances of JRB-1 gasifier are shown below:

\subsubsection{Input parameters for engineering equation solver (EES) simulation}

\section{For wood chips:}

Consumption $=3.1 \mathrm{~kg} / \mathrm{hr}, \mathrm{CH}_{4}=1 \%$, moisture content $=7.36 \%$, element composition = $\mathrm{CH}_{1.586} \mathrm{O}_{0.7089}$, reaction zone temp $=950{ }^{\circ} \mathrm{C}$, charcoal $=3 \%$, gas temp. $=200{ }^{\circ} \mathrm{C}$.

\section{For wood pellets:}

Consumption $=2.9 \mathrm{~kg} / \mathrm{hr}, \mathrm{CH}_{4}=2 \%$, moisture content $=8.55 \%$, element composition $=$ $\mathrm{CH}_{1.615} \mathrm{O}_{0.664}$, reaction zone temp $=1150{ }^{\circ} \mathrm{C}$, charcoal $=3 \%$, gas temp. $=220{ }^{\circ} \mathrm{C}$.

Engineering Equation Solver (EES) simulator output window looked as shown in Fig. 10.

\subsubsection{Engineering equation solver (EES) simulation output}

The simulation outputs are summarized as follows:

For wood chips:

Lower calorific value of gas $(\mathrm{LCV})=5007 \mathrm{~kJ} / \mathrm{m}^{3}$

Cold gas efficiency (LCV of gas vs. fuel) $=69.4 \%$

For wood pellets:

Lower calorific value of gas $(\mathrm{LCV})=4424 \mathrm{~kJ} / \mathrm{m}^{3}$

Cold gas efficiency (LCV of gas vs. fuel) $=62.5 \%$

These output values are found to be close to the experimental results of JRB-1 gasifier. 
E⿱屮凵s File Edit Search Options Calculate Tables Plots Windows Help

\begin{tabular}{|c|c|c|}
\hline \multicolumn{3}{|c|}{ Mass flows } \\
\hline & Mass flows & $\%$ of wood chips \\
\hline Dry wood chips & 3.1 [kg/h] & $100.0[\%]$ \\
\hline Moisture & $0.2463[\mathrm{~kg} / \mathrm{h}$ & $7.9[\%]$ \\
\hline Steam & $0[\mathrm{~kg} / \mathrm{h}]$ & $0.0[\%]$ \\
\hline Air & $6.3[\mathrm{~kg} / \mathrm{h}]$ & $203.2[\%]$ \\
\hline
\end{tabular}

\begin{tabular}{|l|c|c|}
\hline \multicolumn{3}{|c|}{ Gas composition } \\
\hline & Dry base & Wet base \\
\hline $\mathbf{C O}$ & $21.9[\mathrm{Vol} \%]$ & $19.5[\mathrm{Vol} \%]$ \\
$\mathrm{CO} 2$ & $10.4[\mathrm{Vol} \%]$ & $9.2[\mathrm{Vol} \%]$ \\
$\mathrm{CH} 4$ & $\mathbf{1 . 0}[\mathrm{Vol} \%]$ & $0.9[\mathrm{Vol} \%]$ \\
H2 & $17.4[\mathrm{Vol} \%]$ & $15.5[\mathrm{Vol} \%]$ \\
H20 & & $11.2[\mathrm{Vol} \%]$ \\
\hline
\end{tabular}

\begin{tabular}{|l|c|c|}
\hline \multicolumn{3}{|c|}{ Energy balance } \\
\hline & Energy & $\%$ of thermal inpu \\
\hline Thermal input & $15.72[\mathrm{~kW}]$ & $100.0[\%]$ \\
Preheating of dry wood chips & $0.0[\mathrm{~kW}]$ & $0.0[\%]$ \\
Preheating of moisture & $0.0[\mathrm{~kW}]$ & $0.0[\%]$ \\
Preheating of air & $0.0[\mathrm{~kW}]$ & $0.0[\%]$ \\
Preheating of steam & $0.0[\mathrm{~kW}]$ & $0.0[\%]$ \\
\hline Internal energy in gas & $10.91[\mathrm{~kW}]$ & $69.4[\%]$ \\
Cooling of gas & $2.833[\mathrm{~kW}]$ & $18.0[\%]$ \\
Energy in char coal out & $0.8[\mathrm{~kW}]$ & $4.9[\%]$ \\
Heat loss & $0.3[\mathrm{~kW}]$ & $2.0[\%]$ \\
\hline
\end{tabular}

\section{Gasifier}

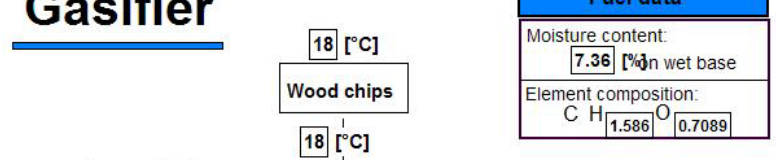

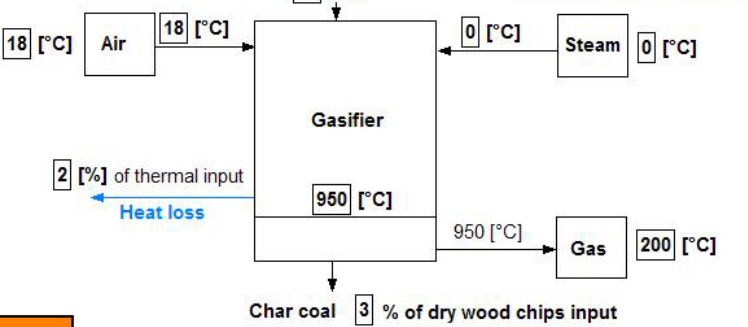

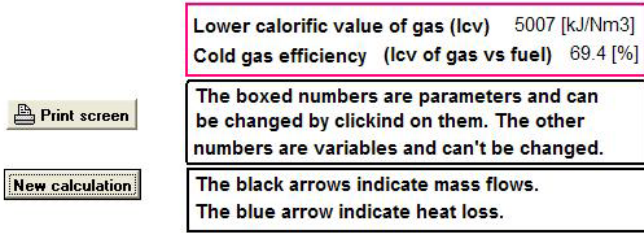

This model can be used for free. If results from the model are used in publication please refer to Felicia Fock and Kirstine Thomsen, 2000, DTU, MEK, Denmark. We do not take responsibility for the consequences of the use of the model.

Fig. 10. Engineering Equation Solver (EES) simulator output window for JRB-1 gasifier.

\subsection{Limitations of the existing gasifier operation}

The small JRB-1 downdraft biomass gasifier was developed for testing purpose only. Therefore a number of technical and operational limitations remain with the existing gasifier:

a. The gasifier was not built for continuous operation. At each refuelling, the top cover needed to be opened and this caused a lot of air leakage and heat loss.

b. The design did not include any special fuel feeding hopper. Instead, a simple small fuel feeding hole was used. Feeding of biomass was tough and time consuming.

c. There was no proper ignition port to initiate the combustion in the oxidation zone.

d. Since the stirrer was attached to the top cover plate, its opening, fuel feeding and operation process was always very difficult.

e. Since the air intake manifold was square in shape and air was supplied from one corner, air was not uniformly distributed in the oxidation zone.

\subsection{Feasible applications of JRB-1 gasifier in developing countries}

Biomass gasifier like JRB-1 could have many potential applications, including: 
1. Direct thermal application in agro industries for its ability to produce higher temperatures, better control, enhancement of boiler and total efficiency, lower emissions etc. It could be used as dryer in tea and cardamom industries; tiles, potteries, ceramic industries; to run furnaces in metallurgical industries where high temperatures (up to $1000{ }^{\circ} \mathrm{C}$ ) is required; to run boiler in process industries etc.

2. Shaft power applications in agriculture sector, i.e. harvesters, tractors, grinding machines etc. Another potential application in the agriculture sector is irrigation.

3. Combined Heat and Power (CHP) application and Stand-alone power systems.

4. Distributed power generation and Chemical production.

\section{Conclusion}

Biomass gasification offers one of the most promising renewable energy systems for developing countries. A more extensive and attractive system could be a downdraft gasifier capable of generating sufficiently low tar content syngas for engine applications. The biggest challenge in gasification system is reliable and economical cooling and cleaning technology. The successful JRB-1 gasifier at Durham University opens a door to ensure effective use of biomass and reduce emission in agro industries. Finally we can say, being comparatively easy to build with low cost materials, downdraft gasifiers like JRB-1 could be an attractive technology for thermal and power applications in developing countries.

\section{Acknowledgments}

We are grateful to Dr. Jim Bumby, Mr. Bernd Kammerich, Mr. Colin Wintrip and all other staffs in Mechanical, Electrical and Electronic and Civil Laboratory of Durham University, UK for their active help and guidance during the construction and testing of JRB-1 gasifier.

\section{Reference}

1. S. Chopra and A. A. Jain, Review of Fixed Bed Gasification Systems for Biomass, CIGR ejournal, Invited Overview No. 5, Vol. IX (April 2007).

2. J. Rezaiyan and N. P. Cheremisinoff, Gasification Technology, A Primer for Engineers and Scientist (CRC Press, Taylor \& Francis Group, Boca Raton, 2005).

3. M. L. Souza-Santos, Solid Fuels Combustion and Gasification: modeling, simulation, and equipment operation (CRC Press, New York, 2004). doi:10.1201/9780203027295

4. C. Hgman and M. Van der Burgt, Gasification, $2^{\text {nd }}$ Edition (Elsevier Inc. Oxford, 2008).

5. T. B. Reed and A. Das, Handbook Biomass Downdraft Gasifier Engine systems, Solar Technical Information Program (U.S. Department of Energy, Colorado, 1988).

6. A. K. Rajvanshi, Biomass Gasification, in: Alternative Energy in Agriculture, Y. Goswami (ed.), Vol. II (CRC Press, U.S.A., 1986).

7. J. R. Gross, State of Art of Agriculture Residue Gasifier in the U.S., First USAID/GOI Workshop on Alternative Energy Resources and Development (New Delhi, November 1983).

8. G. Maschio, Production of Syngas from Biomass, Dipartimento di Chimica Industriale, Universitd di Messina, CP 29-98166 S (Agata di Messina, Italy, 1993). 